\title{
ASTROCYTES ARE VERY SENSITIVE TO DEVELOP INNATE IMMUNE RESPONSES TO SHORT INTERFERING RNA
}

Roser Gorina, Tomàs Santalucia, Valérie Petegnief, Aroa Ejarque-Ortiz, Josep Saura, and Anna M. Planas*

Department of Brain Ischemia and Neurodegeneration, Institut d'Investigacions Biomèdiques de Barcelona (IIBB)-Consejo Superior de Investigaciones Científicas (CSIC), IDIBAPS, Barcelona, Spain.

*Address correspondence to:

Anna M. Planas, IIBB-CSIC, IDIBAPS, Rosselló 161, planta 6, E-08036-Barcelona, Spain, Tel. +34-93 3638327 Fax: +34-93338301

e-mail: ampfat@iibb.csic.es 


\section{ABSTRACT}

Short interfering RNA (siRNA) inhibits the synthesis of specific proteins through RNA interference. However, in cells of the immune system, such as dendritic cells, siRNA can induce innate immune responses that are mediated by Toll-Like Receptors (TLRs). Here we sought to evaluate whether siRNA can induce such responses in astrocytes, as these cells are active players in cerebral innate immunity and express TLRs. We examined the effects of various siRNAs (6 silencing sequences targeting specific genes and 2 non-silencing control sequences). siRNA sequences induced variable degrees of silencing-independent non-specific effects, e.g. increased Stat 1 expression and release of IL-6 and IP-10 in primary cultures of astroglia. These effects could be prevented through chemical modification of siRNA by nucleoside 2'-Omethylation in the sense strand, without impairing the specific gene silencing effect. Primary astroglia cultures contain non-negligible proportions of microglia. However, siRNA also induced non-specific responses in purified astroglia, but not in microglia or 3T3 cells. Microglia showed higher TLR7 mRNA expression than primary or purified astroglia and 3T3 cells, whereas TLR3 mRNA expression was higher in cultures containing astroglia than in microglia or 3 T3 cells. Accordingly, the TLR3 agonist poly(I:C) (PIC) induced higher release of IFN- $\beta$ in primary astroglia and purified astroglia than in microglia. As siRNA, PIC induced IP-10, Stat1, VCAM-1 and COX-2 and increased the expression of TLR3 mRNA. These results show that astroglia is particularly sensitive to develop innate immune responses against siRNA sequences, and suggest that this might be mediated, at least in part, by activation of TLR3.

Key words: Stat1, IP-10, IL-6, glia, microglia, TLR

Running title: Immune response to siRNA in astroglia 


\section{INTRODUCTION}

Cells of the immune system have the ability to develop qualitatively different innate immune responses depending on the cell type, the nature of the pattern recognition receptor, and the tissue microenvironment (Colonna et al., 2006). In the central nervous system (CNS), stimulation of innate immune responses depends on the cell type and the environmental signal (Jack et al., 2005). Microglial cells are regarded as the CNS resident immune cells (Block and Hong, 2005). Nevertheless, astrocytes are also important mediators of cerebral immune and inflammatory reactions (Dong and Benveniste, 2001), and the view is growing on the importance of astrocytes in cerebral innate immune responses (Farina et al., 2007, Falsig et al., 2006; Scumpia et al., 2005).

The innate immune response is a defence mechanism triggered by infectious agents and other molecules. Host defence against virus infection involves the recognition of viral nucleic acids mediated by innate immune pattern recognition receptors, including membrane-bound Toll-like receptors (TLRs), which recognize double-stranded (ds) RNA, single-stranded (ss) RNA and dsDNA. TLRs can then activate antiviral gene programs (Doyle et al., 2003) mediated by induction of type I interferon and inflammatory cytokines (Kawai and Akira, 2006). Besides TLRs, cytoplasmic RNA helicases, such as Protein-Kinase R (PKR) and RIG-I, are important cytoplasmic sensors of viral infection that become activated by dsRNA (Jefferies and Fitzgerald, 2005).

Short interfering RNAs (siRNAs) are used in living cells and organisms to silence RNA coding for specific proteins through RNA interference (RNAi). Yet, it is now recognised that siRNAs can induce non-specific effects by activating the innate immune response (Sledz et al., 2003); particularly when they are combined with lipids, as for in vitro cell transfection (Hornung et al., 2005) and to avoid serum nuclease degradation in vivo (Judge et al., 2005, 2006). Living organisms and cultured dendritic cells and macrophages exposed to siRNAs show up-regulation of type-I interferon (IFN) and a subsequent increase in the expression of signal transduction and activator of transcription-1 (Stat1), an interferon-stimulated gene that mediates 
innate immunity (Durbin et al., 1996), and they release various cytokines (Sledz et al., 2003; Karikó et al., 2004a). Although these unwanted effects do not seem to prevent the expected RNAi, they cause a huge drawback for the therapeutical use of siRNA, and they may confound the biological effect of RNAi.

Whether siRNA can induce immune responses in glial cells has not been investigated so far. Here we examined whether a variety of siRNAs can trigger immune responses in different types of mouse brain glia cultures and, for comparison purposes, we also used non-glial cells. We then tested whether the effects of siRNA could be prevented by 2'-O-methylation of uridine or guanosine nucleosides of the siRNA sense strand, and compared the effects of siRNA with those induced by the TLR3 agonist poly(I:C) (PIC).

\section{MATERIALS AND METHODS}

\section{Cell cultures}

Animal work was authorised by the Ethical Committee of the University of Barcelona and it was performed in agreement with the local regulations. Primary cultures of glial cells were prepared as reported (Saura et al., 2003). Cerebral cortices from 1- to 2-day-old Swiss CD1 mice (Charles-River, France) were used. Culture medium was Dulbecco's modified Eagle medium:F-12 nutrient (DFF) (1:1) (Gibco-BRL), supplemented with 10\% foetal bovine serum (FBS) (Gibco-BRL), and $4 \mathrm{~mL} / \mathrm{L}$ of 10,000U/mL penicillin/10,000 $\mu \mathrm{g} / \mathrm{mL}$ streptomycin (GibcoBRL). All products and reagents, unless otherwise stated, were from Sigma-Aldrich. Cells were plated in 24-well plates (NUNC, Roskilde, Denmark) and maintained in DFF and 10\% FBS with antibiotics, as above. Medium was replaced every 4-5 days and confluency was achieved after 10-12 days in vitro. These cell cultures contain astrocytes and around $25 \%$ of microglia (Gorina et al, 2007).

Enriched astroglia cultures were prepared following a reported procedure (Gorina et al., 2007). Mouse primary mixed glial cultures on 10-12 DIV were treated with $10 \mu \mathrm{M}$ of the antimitotic cytosine arabinoside (Ara-C, Sigma-Aldrich) for 4 days to eliminate dividing cells, 
i.e. mostly microglia and progenitors, but not quiescent cells, i.e. mostly confluent astrocytes. The adherent cells were detached with trypsin $0.05 \% /$ EDTA $0.2 \mathrm{mM}$ and seeded at $6 \times 10^{4}$ cells $/ \mathrm{mL}$ with culture medium (see above). Astrocytes were used two days after subculturing and they contained more than $96 \%$ astrocytes (Gorina et al., 2007).

Microglial cells were obtained by mild trypsinization with a method yielding high purity (>98\%) (Saura et al, 2003; Gorina et al., 2007), and they were used one day after isolation.

Primary glial cultures were also obtained from homozygous Stat1 -/- mice (129S6/SvEv background) and from the corresponding controls (129S6/SvEv wild type, WT) (Taconic Farms, Germantown, NY, USA ).

NIH3T3 cells (American Type Culture Collection, Manassas, VA, USA) were maintained in Dulbecco's modified Eagle's medium supplemented with $10 \%$ bovine serum and antibiotics, as above. For transfection, $5 \times 10^{4}$ NIH3T3 cells were plated in 24-well plates.

\section{siRNA treatment}

Cell cultures were exposed to siRNAs for several time periods ranging from 30 min to 6 days. The typical concentration of siRNA used was $100 \mathrm{nM}$, but a range of concentrations (from 0.01 to $100 \mathrm{nM})$ was tested. In addition, high siRNA concentration $(3.3 \mu \mathrm{M})$ was used in one set of experiments designed to examine whether siRNA could induce TLR mRNA expression (see below). siRNA was mixed with oligofectamine ${ }^{\mathrm{TM}}$ (Invitrogen) 15 min at RT prior to cell transfection. The final concentration of oligofectamine in the culture medium was $4 \mu \mathrm{g} / \mathrm{mL}$. Control cultures were treated with oligofectamine in the absence of siRNA. Two kinds of silencing siRNAs were used, either consisting of a population of multiple duplex sequences against Stat1 (\#RM-1171), GAPDH (\#RM-0057), and Jak2 (\#RM-1164) (Superarray Bioscience Corporation), or consisting of one unique duplex sequence (Qiagen) against MAPK1 (ERK) (\#1022564) or p21Cip1/Waf1 (p21-Q) (\#1024837). In addition, we obtained the latter duplex sequence against p21 (antisense: C.G.A.A.G.U.C.A.A.A.G.U.U.C.C.A.C.C.G.dT.dT, sense: C.G.G.U.G.G.A.A.C.U.U.U.G.A.C.U.U.C.G.dT.dT) from a different source, as it was custom made by another supplier (p21-D1; Dharmacon). Also, a different commercially available 
duplex sequence (p21-D2) against p21 was tested (ON-TARGET plus ${ }^{\mathrm{TM}}$ duplex J-0586636-05, Mouse CDKN1a, NM_007669, Dharmacon). According to the supplier, ON-TARGETplus ${ }^{\mathrm{TM}}$ modification enhances siRNA specificity and reduces off-target effects. Also, two different nonsilencing siRNAs were used as controls for the RNAi effect. One of these (ns-m) was composed of a population of duplex sequences (\#RM-1171 negative control, Superarray Bioscience Corporation), and the other (ns) consisted of one duplex sequence (\#1022076, Qiagen). According to the manufacturers, the sequences of the non-silencing siRNAs had no homologies with the known rodent genes and they were used as negative controls.

\section{siRNA modifications}

The siRNA sequence against p21 (p21-Q and p21-D1) was modified by introducing 2'-Omethylation (m) in nucleosides of the sense sequence; either in all uridine nucleosides (C.G.G.mU.G.G.A.A.C.mU.mU.mU.G.A.C.mU.mU.C.G.dT.dT), or in all guanosine nucleosides (C.mG.mG.U.mG.mG.A.A.C.U.U.U.mG.A.C.U.U.C.mG.dT.dT), while keeping the antisense sequence unmodified (C.G.A.A.G.U.C.A.A.A.G.U.U.C.C.A.C.C.G.dT.dT). These siRNAs were custom made upon request (Dharmacon).

\section{Other treatments}

Cells were treated with the synthetic double-stranded RNA, polyinosinic-cytidylic acid (poly(I:C), PIC)) (Sigma) (50 or $100 \mu \mathrm{g} / \mathrm{mL}$ ), and cells and media samples were obtained at several time points ranging from 4 to $24 \mathrm{~h}$ for Western blot and ELISA measurements. Exposure to chloroquine (50 $\mu \mathrm{g} / \mathrm{mL}$, Sigma) was initiated two hours prior to PIC or siRNA treatment.

\section{Western blotting}

Western blotting was performed as described (Gorina et al., 2005) with monoclonal antibodies against Stat1 and Stat3 (BD Transduction Laboratories) diluted 1:4,000; p21 (BD Pharmingen) diluted 1:2000; panERK (Cell Signaling) diluted 1:8,000; iNOS (BD Transduction 
Laboratories) diluted 1:1,000; and phosphorylated eIF2 $\alpha$ (peIF2 $\alpha$ ) (Epitopics) diluted 1:1000. The following polyclonal antibodies were used: a goat antibody against VCAM-1 (Santa Cruz Biotechnology Inc.) diluted 1:1000; and a rabbit antibody against COX-2 (Cayman Chemical Co) diluted 1: 1000. $\beta$-Tubulin diluted 1:50,000, or actin diluted 1:10,000 (Sigma-Aldrich) were used as loading controls. The optical density of the bands was measured by densitometric analysis (Kodak Digital Science 1D, Kodak). The ratio between band intensity of specific proteins and the corresponding loading control was calculated to correct for differences in protein gel loading. For each gel, these ratio values were expressed as percentage of the control samples run in the same gel. Then, the average of the values (percent of corresponding control) of various samples of the same treatment group ( $\mathrm{n}=3$ or more) that were run in different gels was calculated and statistical analysis was performed to test whether differences were statistically significant.

\section{Immunocytochemistry}

To verify that siRNA was entering the cells we incubated either pure cultures of astrocytes or pure microglia with a fluorescent rhodamine-labelled control non-targeting siRNA sequence (100 nM, \#D-001600-01) for 24h and then examined the cells under the microscope. Double labelling was carried out with fluorescent-siRNA and a rabbit polyclonal antibody against the astroglial marker glial fibrillary acidic protein (GFAP) (\#Z0334, Dako) diluted 1:1,000, or with a mouse monoclonal antibody against the microglial marker ED1 (\#MCA341R, Serotec), diluted 1:100). The secondary antibodies were green-fluorescent Alexa Fluor 488 dye-labelled goat anti-rabbit IgG (\#A-11070; Molecular probes) or goat anti-mouse IgG (\#A-11017, Molecular Probes). After the immunoreaction, cells were stained with Hoecht to visualise the nuclei.

\section{ELISA Assays}

The concentrations of IP-10 (Quantikine murine IP-10/CRG-2/CXCL10, \#MCX100, R\&D Systems Europe, Ltd. Abingdon, UK), IP-9 (Quantikine murine CXCL9/MIG, \#MCX900, R\&D 
Systems), IL-6 (\#860.020.192, Diaclone SAS, Besançon, France) and IFN- $\beta$ (\#42400-1, R\&D Systems) in the culture media were determined by ELISA.

\section{Real-time detection of the expression of TLR3 and TLR7 mRNA}

RNA was extracted using guanidinium thiocyanate (Chomczynski \& Sacchi, 1987). Two $\mu \mathrm{g}$ of RNA were used for cDNA synthesis using the AMV First-Strand cDNA Synthesis Kit (\# 12328-040, Invitrogen, Carlsbad, Ca, USA). Two $\mu$ of cDNA synthesis reaction were used in a $25 \mu$ real-time PCR reaction with FAM-labelled Taqman ${ }^{\circledR}$ Gene Expression Assays for TLR3 (Mn00446577_g1), TLR7 (Mn00446590_m1), and $\beta$-actin (Mn00607939_s1) (Applied Biosystems, Foster City, CA, USA). The amplification conditions were: $10 \mathrm{~min}$ at $95^{\circ} \mathrm{C}$ followed by 40 cycles of $15 \mathrm{sec}$ at $95^{\circ} \mathrm{C}, 1 \mathrm{~min}$ at $60^{\circ} \mathrm{C} . \mathrm{C}_{\mathrm{T}}$ values were analyzed using the $2^{-}$ $\Delta \Delta \mathrm{C}$ T method (Livak \& Schmittgen, 2001).

\section{Data analyses}

Results are the mean of 3 to 9 independent experiments. The effects of siRNA treatment were analysed with one-way ANOVA. Comparison for treatments and cell types was made by twoway ANOVA. Thereafter the effect of individual treatments was evaluated by post-hoc analysis with the Bonferroni's multiple comparisons test. Data not passing the normality test (D'Agostino \& Pearson omnibus test) were analysed with the non-parametric Kruskal-Wallis test followed by Dunn's multiple comparison test. Statistical analyses were performed using GraphPad Prism software. 


\section{RESULTS}

\section{siRNA reduced the expression of specific proteins, but not of Stat1}

Primary astroglial cell cultures were exposed to several siRNA sequences to induce RNAi. siRNA was mixed with oligofectamine for transfection and cells not receiving siRNA were exposed to oligofectamine alone. We used non-silencing siRNA sequences as negative controls, Treatments with certain siRNAs successfully silenced targeted genes in these cultures by reducing the expression of the corresponding proteins, as illustrated with siRNA against p21 (Fig. 1A) and ERK (Fig. 1B). However, when we tried to silence the interferon (IFN)responsive protein Stat1 with siRNA, we found an increase in Stat1 protein expression, instead of a reduction (Fig. 1C). Control non-silencing siRNA (ns), which did not target specific proteins, also increased Stat1 expression (Fig. 1C) suggesting that siRNA induced Stat1 expression in a non-specific manner in primary astroglia cultures. In addition, a tendency to increase p21 protein expression was also found after treatment with ns siRNA (Fig. 1A). Bhunia et al. (2002) reported that the JAK-STAT pathway was involved in p21 induction. For this reason we tested whether non-silencing siRNA was still capable of inducing the small increase in p21 protein in Stat1 deficient cultures. The results showed a similar increase in p21 in Stat1 deficient cells (not shown), and therefore we could not evidence a link between increases in Stat 1 and 21 proteins induced by the non-silencing siRNA sequence.

\section{siRNA induced Stat1 expression in primary glial cell cultures}

Non-silencing (ns) siRNA that was used as negative control was capable of inducing the expression of Stat1 in primary astroglia cultures at different time points (Fig. 2A), but it did not affect Stat3 expression (Fig. 2B). The effect was observed from $12 \mathrm{~h}$ to 6 days, with a maximum around 4 days (Fig. 2A). We then tested various siRNA sequences directed against specific targets (such as GAPDH, Jak2, Stat1, p21 and ERK) as well as other negative control nonsilencing sequences $\left(\mathrm{ns}_{\mathrm{m}}, \mathrm{ns}\right)$ for their capacity to induce the expression of Stat 1 in our cultures. We found that the sequences tested induced variable degrees of Stat 1 protein expression (Fig. 2 
C). This suggests that induction of Stat1 was a non-specific effect of siRNA, which was independent of its silencing effect, and that the intensity of the effect depended on the siRNA sequence. The observed Stat 1 induction did not alter the capacity of siRNA to silence targeted genes that were not related with the immune response, as shown for p21 and ERK (Fig. 1A, B).

The concentration of $100 \mathrm{nM}$ was chosen in this study as it induced a significant reduction of protein expression, as shown for p21 siRNA in Fig. 3A. siRNA-induced Stat1 expression was concentration-dependent; it was already statistically significant at $10 \mathrm{nM}$ and increased at 100 $\mathrm{nM}$, as shown for exposure to p21 siRNA in Fig 3B.

In an effort to elucidate whether Stat1 induction was caused by a given siRNA sequence or it might be due to any other possible feature of the siRNA product, we obtained the same siRNA sequence from different suppliers. This experiment was carried out for the p21 sequence used above (p21-Q) (presented in Fig. 1 and 2) that was custom made by a different supplier (p21D1) (see Methods). Both siRNA products were capable of silencing p21 to a similar extent (Fig. 3C), and produced a similar degree of Stat1 induction (Fig. 3D). The result showed that this particular siRNA sequence against p21 triggered Stat1 induction. Finally, we also tested a different commercially available sequence against p21 (p21-D2). The latter also silenced p21 (Fig. 3C) while it did not induce Stat1 expression (Fig. 3D), again supporting the view that siRNA-induced Stat1 was dependent on the siRNA sequence and independent of the silencing effect.

Besides increased Stat1 expression, other non-specific effects of siRNA were detected at 1 and 4 days, including release of IFN-inducible protein 10 (IP-10), IL-6, and IP-9 (see below in Fig. 4). However, we did not find increases in eIF $2 \alpha$ phosphorylation from 30 min to $4 \mathrm{~d}$ after siRNA exposure (not shown), suggesting that the non-specific effects of siRNA were not mediated by activation of PKR.

\section{Stat1 induction was prevented by selective 2'-O-methylation of certain nucleosides}

It was reported (Judge et al., 2005) that the siRNA-induced immune response could be inhibited by 2'-O-methylation of certain nucleosides in the sense strand of the siRNA duplex. 
Here we tested whether this strategy was effective in our primary astroglia culture system. We designed two modified siRNAs from the sequence of the siRNA against p21 by introducing 2'O-methylation in the uridine or guanosine nucleosides of the sense strand. The modifications did not impair the capacity to silence p21 (Fig. 4A, B). In addition, 2'-O'methylation of the guanosine nucleosides effectively reduced Stat1 induction (Fig. 4C, D) and release of IL-6 (Fig. 4E), IP-9 (Fig. 4F) and IP-10 (Fig. 4G), whereas no effect was apparent upon modification of the uridine nucleosides (Fig. 4). The former modification prevented the release of IP-10 even in cultures of Stat1-deficient cells (Fig. 4H), indicating that it abrogated Stat1-dependent and Stat1-independent responses induced by siRNA. These findings show that the siRNA-induced immune response can be prevented by selective nucleoside modification.

\section{Effect of siRNA in different cell types}

The primary astroglial cultures used here contain mainly astrocytes but, to a lesser extent, they also contain non-negligible amounts of microglia. We then questioned whether residual microglia growing in the primary astroglial cultures, rather than the astrocytes, might be responsible for the non-specific effects of siRNA. We subcultured astroglia in order to obtain a higher purity in astrocytes, while the microglia were kept as a separate culture (see Methods). We tried several siRNAs in the different cultures (the negative control non-silencing is shown in Fig. 5A as a representative example). siRNA increased the expression of Stat1 in astroglia but not in microglia, which already showed comparatively higher basal levels of Stat 1 than mixed glia and astroglia (Fig. 5 A, B). This shows that astroglial cells are particularly sensitive to activate a Stat1-mediated immune response after exposure to siRNA.

In addition to Stat1, the concentration of the chemokine IP-10 increased to different extents at 24 and $96 \mathrm{~h}$ after siRNA treatment in the medium of primary astroglia cultures and in purified astroglia, but it was not detected in microglia (Fig. 5C). Likewise, IL-6 was induced by certain siRNAs in primary astroglia cultures and in pure astroglia, but not in microglia (Fig. 5D). Another chemokine, IP-9, showed small increases after exposure to certain siRNAs in mixed astroglia cultures only (Fig. 5E). We also examined iNOS expression, which at the basal state 
was already very high in microglial cultures and moderate in mixed glia, while it was not detected in purified astrocytes (Fig. 5F). siRNAs induced small increases of iNOS expression in primary astroglia cultures $(\mathrm{p}<0.05)$, but significant changes were not detected in pure microglia and no signal was found in pure astroglia (Fig. 5F). These results suggest that the behaviour of astrocytes was different depending on whether they were cultured in the presence or absence of microglia, and that primary astroglia cultures were more responsive to siRNA than secondary purified astroglia cultures.

In order to verify that the lack of response of microglia was not attributable to deficient siRNA transfection, we incubated either purified astroglia or purified microglia with a red fluorescent control siRNA sequence. Fig. 6 shows that siRNA entered astroglia and microglia, which were immunostained with GFAP and ED1, respectively.

We also tested whether siRNA was able to induce the above non-specific responses in an epithelial cell line (NHI3T3). However, in these cells we did not detect effects on Stat1 expression (Fig. 7A,B) nor in IP-9, IP-10 and IL-6 release (not shown), in spite of the fact that the expected silencing effect of siRNA was observed (Fig. 7C, D).

\section{Expression of TLR3 and TLR7 and effect of the TLR3 agonist poly(I:C) (PIC) in different cell cultures}

The highest expression of TLR7 mRNA was found in purified microglia whereas a comparatively lower expression was found in mixed astroglia and in purified astroglia (Fig. 8A). The inverse situation was found for TLR3 mRNA, as the highest expression was found in primary astroglia cultures, followed by cultures of pure astroglia, and to a much lower extent in pure microglia (Fig. 8B). Altogether, these results suggest that in astroglia TLR3 might mediate, al least in part, the immune effects of siRNA. In 3T3 cells, expression of TLR7 (Fig. 8A) and TLR3 (Fig 8B) mRNA was low, in agreement with the lack of immune response of these cells to siRNA treatment. We also tested whether treatment with siRNA or with the TLR3 agonist PIC modified the level of TLR3 and TLR7 mRNA expression. Incubation for 24h with either PIC $(50 \mu \mathrm{g} / \mathrm{mL})$ or with a high dose of siRNA $(3.3 \mu \mathrm{M}$, i.e. approximately $50 \mu \mathrm{g} / \mathrm{mL})$ increased 
the expression of TLR3 mRNA, but this effect was not observed with the siRNA dose used for silencing gene expression (100 nM) (Fig. 8C). However, neither siRNA nor PIC increased the expression of TLR7 mRNA at these doses (not shown).

We then tested the effect of PIC on release of IFN- $\beta$ in the different glia cultures. PIC induced a much higher IFN- $\beta$ release in primary astroglia cultures and in pure astroglia, than in microglia (Fig. 8D). This effect was in accordance with the expression of TLR3 mRNA observed above in the different cell types.

Besides the above effect of PIC, this TLR3 agonist increased the expression of Stat1, VCAM1, and Cox-2 (Fig 8E), in agreement with previous reports (Scumpia et al., 2005; KrasowskaZoladek et al., 2007; Park et al., 2006). siRNA treatment also induced VCAM-1 and Cox-2 expression, as PIC did. These effects of PIC and siRNA were abolished by pre-treatment with the endosomal acidification inhibitor chloroquine, suggesting that internalization to mature endosomes might be involved in the observed responses (Fig. 8F).

\section{DISCUSSION}

Here we report that 1) siRNA can induce a non-specific innate immune response associated with induction of Stat1 expression and release of cytokines and chemokines in astroglia; 2) this effect does not prevent silencing of specific targets; 3) the intensity of the response varies depending on the siRNA sequence; 4) siRNA modification by 2'-O-methylation of certain nucleosides of the sense sequence can abrogate this response while keeping the RNAi effect; and 5) these non-specific effects of siRNA in astroglia might be mediated, at least in part, by TLR3.

A variety of siRNA sequences induced Stat1 expression and release of cytokines and chemokines, and we also evidenced a tendency to increase in p21 protein expression by certain siRNAs. The JAK-STAT pathway can be involved in p21 induction (Bhunia et al., 2002), however here we could not find an association between siRNA-induced Stat1 and p21 by examining p21 expression in Stat1 deficient cells. Also, siRNA-induced release of IP10 was 
observed in Stat1 deficient cells. Unless there were unknown compensatory mechanisms in Stat1-deficient cells, these findings suggest that, besides Stat1, other pathways might be affected by siRNA treatment in a non-specific manner.

We characterised non-specific effects of siRNAs in cultures of different cell types by studying the induction of Stat1, and release of proinflammatory cytokines and chemokines. Primary cultures of astroglia were particularly prone to show Stat1 induction, release of IP-10, IL-6, and IP-9, and increase in iNOS expression after exposure to siRNA. In purified astrocytes, we also observed induction of Stat1, IP-10 and IL-6, but not of IP-9 or iNOS, but, we did not detect increases in the expression of these molecules in microglia or epithelial 3T3 cells. Therefore, astrocytes emerged as cells responsive to siRNA that can generate an innate immune response against it. The different response of glia depending on whether astroglia and microglia were cultured separated or combined shows that the capacity of the cells to respond to immunostimulatory agents may depend on particular culture conditions. This suggests that the cellular phenotype of astroglia is altered by the presence of microglia, and vice versa.

RNA helicases, such as PKR, are important cytoplasmic sensors of viral infection that become activated by dsRNA (Jefferies and Fitzgerald, 2005). After viral infection, PKR is involved in IFN induction (Diebold et al., 2003), and phosphorylates certain factors involved in translation, such as eukaryotic initiation factor $2 \alpha$ (eIF2 $\alpha$ ) (Srivastava et al., 1998). In several cell lines, siRNA has been reported to activate PKR (Sledz et al., 2003). However, in astroglia, we did not detect phosphorylation of eIF $2 \alpha$ after exposure to siRNA, suggesting that this process is not responsible for the immune response induced by siRNA in these cells. In plasmacytoid dendritic cells, siRNA induces IFN- $\alpha$ through TLR7 (Hornung et al., 2005), which is known to mediate the recognition of single-stranded RNA (Lund et al., 2004). Signaling through TLR3 might also be involved in the immune responses to siRNA (Karikó et al., 2004a, b). TLR3 mediates cellular responses to dsRNA (Alexopoulou et al., 2001) and induces downstream selective activation of IFN regulatory factor 3 (IRF3) (Doyle et al., 2002). Astrocytes express TLRs (Farina et al., 2005; Jack et al., 2005; Konat et al., 2006) and respond to certain viruses and to 
the TLR3 ligand PIC (Scumpia et al., 2005; Carpentier et al., 2007; Krasowska-Zoladek et al., 2007; Park et al., 2006; Rivieccio et al., 2006; Vincent et al., 2007). We found that our astroglia cultures were comparatively richer in TLR3 mRNA than in TLR7 mRNA, while we found the reverse situation for microglia. In agreement with higher TLR3 expression in astroglia than in microglia, the TLR3 agonist PIC induced much higher IFN- $\beta$ release in cultures containing astroglia than in pure microglia. Also, PIC induced a variety of other effects in astroglia that were similar to those induced by siRNA. The effects of both agents were attenuated by the endosomal acidification inhibitor chloroquine, suggesting that intracellular TLR3 might contribute to mediate non-specific effects of siRNA in astroglia. However, previous findings (Bsibsi et al., 2002) have shown preferential expression of TLR3 in the astroglia membrane. Therefore, we cannot exclude the participation of membrane TLR3 in siRNA-induced immune responses. Pro-inflammatory cytokines, TLR3 or TLR4 agonists, and oxidative stress induce TLR expression in human astrocytes (Bsibsi et al., 2006). In agreement with these observations, we found that treatment with a very high dose of siRNA $(3.3 \mu \mathrm{M}$, which is approximately equivalent to $50 \mu \mathrm{g} / \mathrm{mL})$ or with the TLR3 agonist PIC $(50 \mu \mathrm{g} / \mathrm{mL})$ increased TLR3 mRNA expression in our primary astroglia cultures, but this effect was not observed for TLR7 mRNA; again pointing to TLR3 as a possible mediator of siRNA-induced non-specific effects in astroglia.

The effects of siRNAs in our cells occurred regardless of whether the sequences were silencing or not, and were independent on the RNAi effect. Certain motifs have been attributed immunostimulatory properties (Judge et al., 2005; Hornung et al., 2005). In agreement with this, the induction of the immune response studied here in glia was sequence-specific, as its magnitude was variable depending on the siRNA sequences, as previously reported in other cells (Hornung et al., 2005; Judge et al., 2005; Sioud 2005). We carried out two different modifications on the siRNA sequence against p21 aiming to attenuate this non-specific response. We designed 2'-O-methylation of either uridine or guanosine nucleosides of the sense chain, since this strategy was reported to abrogate siRNA-induced immune responses (Judge et 
al., 2006; Sioud 2007). Our results showed that introduction of 2'-O-methyl in all guanosine nucleosides of the sense sequence of the double stranded siRNA duplex prevented Stat 1 and iNOS induction, and IP-10, IP-9 and IL-6 release, while the silencing effect was not impaired. This suggests that nucleoside 2'-O-methylation can be used to abrogate immune responses of siRNA in astrocytes. Therefore, the use of precise siRNA sequences and siRNA modifications intended to avoid non-specific immune responses is important to carry studies of gene silencing in astrocytes.

In conclusion, this study shows that astrocytes are sensitive to develop non-specific innate immune responses to siRNA sequences, and that these responses can be prevented by certain siRNA modifications. In addition, the results suggest that intracellular TLR3 might contribute to mediate non-specific effects of siRNA in astroglia. 


\section{Acknowledgment:}

Supported by National Grants from CICYT (SAF2005-05793) and FIS (FS041104). RG has a PhD fellowship from IDIBAPS. TS, VP, and JS are fellows of the Spanish 'Ramón y Cajal' Program. We thank the helpful technical support of Mr. Felix Gil and Ms. Noelia Montoya.

John Wiley \& Sons, Inc. 


\section{REFERENCES}

Alexopoulou L, Holt AC, Medzhitov R, Flavell RA. 2001. Recognition of double-stranded RNA and activation of NF-kappaB by Toll-like receptor 3. Nature 413:732-738.

Bhunia AK, Piontek K, Boletta A, Liu L, Qian F, Xu PN, Germino FJ, Germino GG. 2002. PKD1 induces p21(waf1) and regulation of the cell cycle via direct activation of the JAKSTAT signaling pathway in a process requiring PKD2. Cell 109:157-168.

Block ML, Homg J-S. 2005. Microglia and inflammation-mediated neurodegeneration: Multiple triggers with a common mechanism. Prog Neurobiol 76:77-98.

Bsibsi M, Persoon-Deen C, Verwer RW, Meeuwsen S, Ravid R, Van Noort JM. 2006. Toll-like receptor 3 on adult human astrocytes triggers production of neuroprotective mediators. Glia 53:688-695.

Bsibsi M, Ravid R, Gveric D, van Noort JM. 2002. Broad expression of Toll-like receptors in the human central nervous system. J Neuropathol Exp Neurol 61:1013-1021.

Carpentier PA, Williams BR, Miller SD. 2007. Distinct roles of protein kinase R and toll-like receptor 3 in the activation of astrocytes by viral stimuli. Glia 55:239-252.

Chomczynski P, Sacchi N. 1987. Single-step method of RNA isolation by acid guanidinium thiocyanate-phenol-chloroform extraction. Anal Biochem 162:156-159.

Colonna M, Pulendran B, Iwasaki A. 2006. Dendritic cells at the host-pathogen interface. Nat Immunol 7:117-120. 
Diebold SS, Montoya M, Unger H, Alexopoulou L, Roy P, Haswell LE, Al-Shamkhani A, Flavell R, Borrow P, Reis e Sousa C. 2003 Viral infection switches non-plasmacytoid dendritic cells into high interferon producers. Nature 424:324-328.

Dong Y, Benveniste EN. 2001. Immune function of astrocytes. Glia 36:180-190.

Doyle SE, O'Connell R, Vaidya SA, Chow EK, Yee K, Cheng G. 2003. Toll-like receptor 3 mediates a more potent antiviral response than Toll-like receptor 4. Immunol. 170:3565-71.

Doyle S, Vaidya S, O'Connell R, Dadgostar H, Dempsey P, Wu T, Rao G, Sun R, Haberland M, Modlin R, Cheng G. 2002. IRF3 mediates a TLR3/TLR4-specific antiviral gene program. Immunity 17:251-263.

Durbin JE, Hackenmiller R, Simon MC, Levy DE. 1996. Targeted disruption of the mouse Stat1 gene results in compromised innate immunity to viral disease. Cell 84: 443-450

Falsig J, Parzgen P, Lund S, Schrattenholz A, Leist M. 2006 The inflammatory transcriptome of reactive murine astrocytes and implications for their innate immune function. $\mathrm{J}$ Neurochem. 96:893-907.

Farina C, Aloisi F, Meinl E. 2007. Astrocytes are active players in cerebral innate immunity. Trends Immunol 28:138-145.

Farina C, Krumbholz M, Giese T, Hartmann G, Aloisi F, Meinl E. 2005. Preferential expression and function of Toll-like receptor 3 in human astrocytes. J Neuroimmunol 159:12-19. 
Gorina R, Petegnief V, Chamorro A, Planas AM. 2005 AG490 prevents cell death after exposure of rat astrocytes to hydrogen peroxide or proinflammatory cytokines : involvement of the Jas2/STAT pathway. J Neurochem 92:505-518.

Gorina R, Sanfeliu C, Galito A, Messeguer A, Planas AM. (2007) Exposure of glia to prooxidant agents revealed selective Stat1 activation by $\mathrm{H} 2 \mathrm{O} 2$ and Jak2-independent antioxidant features of the Jak2 inhibitor AG490. Glia 55:1313-1324.

Hornung V. 2005. Sequence-specific potent induction of INF-alpha by short interfering RNA in plasmacytoid dendritic cells through TLR7. Nat Med 11:263-270.

Jack CS, Arbour N, Manusow J, Montgrain V, Blain M, McCrea E, Shapiro A, Antel JP. 2005. TLR signaling tailors innate immune responses in human microglia and astrocytes. J Immunol 175:4320-4330.

Jefferies CA, Fitzgerald KA. 2005. Interferon gene regulation: not all roads lead to Tolls. Trends Mol Med 11:403-411.

Judge AD, Sood V, Shaw JR, Fang D, McClintock K, MacLachlan I. 2005. Sequencedependent stimulation of the mammalian innate immune response by synthetic siRNA. Nat Biotech 23:457-462.

Judge AD, Bola G, Lee ACH, MacLachlan I. 2006. Design of noninflammatory synthetic siRNA mediating potent gene silencing in vivo. Mol Ther 13: 494-505.

Karikó K, Bhuyan P, Capodici J, Weissman D. 2004a. Small interfering RNAs mediate sequence-independent gene suppression and induce immune activation by signaling through toll-like receptor 3. J Immunol 172:6545-6549.

John Wiley 20 Sons, Inc. 
Karikó K, Bhuyan P, Capodici J, Ni H, Lubinski J, Friedman H, Weissman D. 2004b.Exogenous siRNA mediates sequence-independent gene suppression by signalling through Toll-like Receptors 3. Cells Tissues Organs 177:132-138.

Kawai T, Akira S. 2006. Innate immune recognition of viral infection. Nat Immunol 7:131-137.

Konat GW, Kielian T, Marriott I. 2006. The role of Toll-like receptors in CNS response to microbial challenge. J Neurochem 99:1-12.

Krasowska-Zoladek A, Banaszewska M, Kraszpulski M, Konat GW. 2007. Kinetics of inflammatory response of astrocytes induced by TLR 3 and TLR4 ligation. J Neurosci Res $85: 205-212$.

Livak KJ, Schmittgen TD. 2001. Analysis of relative gene expression data using real-time quantitative PCR and the 2(-Delta Delta C(T)) method. Methods 25:402-408.

Lund JM, Alexopoulou L, Sato A, Karow M, Adams NC, Gale NW, Iwasaki A, Flavell RA. 2004. Recognition of single-stranded RNA viruses by Toll-like receptor 7. Proc Natl Acad Sci USA 101:5598-5603.

Park C, Lee S, Cho IH, Lee HK, Kim D, Choi SY, Oh SB, Park K, Kim JS, Lee SJ. 2006. TLR3-mediated signal induces proinflammatory cytokine and chemokine gene expression in astrocytes: differential signaling mechanisms of TLR3-induced IP-10 and IL-8 gene expression. Glia 53:248-256.

Rivieccio MA, Suh HS, Zhao Y, Zhao ML, Chin KC, Lee SC, Brosnan CF. 2006. TLR3 ligation activates an antiviral response in human fetal astrocytes: a role for viperin/cig5. J Immunol 177:4735-4741.

John Wiley 21 Sons, Inc. 
Saura J, Tusell JM, Serratosa J. 2003. High-yield isolation of murine microglia by mild trypsinization. Glia 44:183-189.

Scumpia PO, Kelly KM, Reeves WH, Stevens BR. 2005. Double-stranded RNA signal antiviral and inflammatory programs and dysfunctional glutamate transport in TLR3-expressing astrocytes. Glia 52:153-162.

Sioud M. 2007. RNA interference and innate immunity. Adv Drug Deliv Rev 59:153-163.

Sioud M. 2005. Induction of inflammatory cytokines and interferon responses by doublestranded and single stranded siRNA is sequence dependent and requires endosomal localization. J Mol Biol 348:1079-1090.

Sledz CA, Holko M, de Veer MJ, Silverman RH, Williams BRG. 2003. Activation of the interferon system by short-interfering RNAs. Nat Cell Biol 5:834-839.

Srivastava SP, Kumar KU, Kaufman RJ. 1998. Phosphorylation of eukaryotic translation factor 2 mediates apoptosis in response to activation of the double-stranded RNA-dependent protein kinase. J Biol Chem 273:2416-2423.

Vincent AJ, Choi-Lundberg DL, Harris JA, West AK, Chuah MI. 2007. Bacteria and PAMPs activate nuclear factor kappaB and Gro production in a subset of olfactory ensheathing cells and astrocytes but not in Schwann cells. Glia 55:905-916. 


\section{FIGURE LEGENDS}

Figure 1. Specific siRNA sequences reduce the level of expression of the targeted proteins. Primary glia cell cultures were exposed to oligofectamine alone (-) as a control, or in combination with various siRNAs $(100 \mathrm{nM})$. The expected RNA interference effect of specific silencing siRNA sequences is obtained in primary glial cultures, as evidenced by Western blot for p21 (A, B) and ERK (C, D) proteins after treatment with p21 siRNA (using the p21-Q siRNA sequence, see Methods) and ERK siRNA, respectively. However, siRNA against interferon-responsive Stat1 increases the expression of this protein (E, F). Control non-silencing siRNA sequences (ns) does not reduce protein expression (A-D), but rather causes a massive increase in Stat1 (E,F) and a non-significant trend to increase in p21 (A,B). (E). Data were obtained in at least 4 independent experiments per siRNA sequence. ${ }^{*} \mathrm{p}<0.05$, $* * \mathrm{p}<0.01, * * * \mathrm{p}<0.001$ versus control (-).

Figure 2. siRNA sequences induce the expression of Stat1 in primary cultures of glia. Cells were exposed to oligofectamine alone (-) as a control, or in combination with various siRNAs (100 nM). A-B) Control non-silencing siRNA (ns) induces significant expression of Stat1 (A), but not Stat3 (B), at the stated time points, as assessed by Western blot. C) Five different silencing siRNAs (against Stat1, GAPDH (GAP), Jak2, p21-Q, and ERK) and two nonsilencing siRNAs (ns and $\mathrm{ns}_{\mathrm{m}}$ ) were tested for Stat1 expression at day 4. The extent of Stat1 induction varies depending on each siRNA. $n$ indicates the number of samples obtained in 3-6 independent experiments per siRNA treatment. $* * * \mathrm{p}<0.001, * * \mathrm{p}<0.01, * \mathrm{p}<0.05$ versus control (-).

Figure 3. Stat1 protein-induction increases as a function of the siRNA concentration and it is dependent on the siRNA sequence, but independent of the silencing effect. A-B) Primary glia cultures were incubated with 1 to $100 \mathrm{nM}$ siRNA against p21 (p21-Q) for 4 days. siRNA significantly silences p21 expression at the dose of $100 \mathrm{nM}(\mathrm{A})$, and it increases Stat1 
expression, in a concentration-dependent manner (B). Samples were obtained in 3-6 independent experiments. ${ }^{*} \mathrm{p}<0.05,{ }^{* * *} \mathrm{p}<0.001$ vs control $(0 \mathrm{nM}$ siRNA in the presence of vehicle). C-D) Primary glia cultures were incubated with different siRNAs against p21 (see Methods) (100 nM), or with vehicle (-). Sequences p21-Q and p21-D1 were identical but obtained from different suppliers. Sequence p21-D2 was different from the former. All sequences have a silencing effect against p21 (C), but only the first sequence (p21-Q and p21D1 siRNAs) induces Stat1 expression whereas the second sequence (p21-D2) does not (D).

Figure 4. O'-methylation of certain nucleosides of the siRNA sense strand abrogates Stat1, chemokine and cytokine induction, without altering the silencing effect. A, B) Expression of p21 is specifically attenuated after treatment with either non-modified p21 siRNA, or with p21 siRNA methylated at uridine- (p21-U) or guanosine- (p21-G) nucleosides, but it is not reduced after treatment with non-silencing control siRNA (ns) or with unrelated siRNA sequences, such as siRNA against ERK $(n=4)$. O'-methylation of $\mathrm{G}$ nucleosides, but not of $\mathrm{U}$ nucleosides, abrogates siRNA-induced Stat1 $(n=4)(C, D)$ and iNOS $(n=3)$ expression (D), and IP-9 (E), IL-6 (F) and IP-10 (n=6) release (G). siRNA-induced IP-10 release is also reduced by G-modification in Stat1-KO mice $(\mathrm{n}=3)(\mathrm{H})$. siRNA concentration was $100 \mathrm{nM}$. Data correspond to the 4-day time point, but Stat 1 and IP-10 were also examined at $24 \mathrm{~h}$ and the same effect was found. $* * * \mathrm{p}<0.001, * * \mathrm{p}<0.01, * \mathrm{p}<0.05$ versus oligofectamine vehicle as control (-); ${ }^{\& \& \&} \mathrm{p}<0.001,{ }^{\&} \mathrm{p}<0.05$ versus $\mathrm{p} 21$ siRNA.

Figure 5. siRNA induces Stat1 expression and cytokine and chemokine release depending on the type of glia culture. A) Stat 1 expression above basal is induced by siRNA in primary cultures of astroglia (primary), and in secondary cultures enriched in astrocytes (astroglia), but not in purified microglia cultures. B) Quantification of the signal $(n=3-6)$ shows statistically significant increases. C, D) siRNA induces release of IP-10 (n=3) (C) and IL-6 (n=4) (D) in primary astroglia cultures and in astrocytes, but not in microglia. E) siRNA also induces a small increase in IP-9 release in primary astroglia only $(n=2)$. F) Basal iNOS expression is 
detected in microglia and, to a lesser extent, in primary astroglia cultures, but not in purified astroglia. A small induction of iNOS expression is apparent after siRNA in primary astroglia $(n=3)$. Illustrated data correspond to the 4-day time point. siRNA concentration was $100 \mathrm{nM}$. $* * * \mathrm{p}<0.001, * * \mathrm{p}<0.01, * \mathrm{p}<0.05$ versus the oligofectamine vehicle (-).

Figure 6. siRNA is internalized into astrocytes and microglia. Purified astroglia (A, B, C) and microglia (D, E, F) cells were treated with $100 \mathrm{nM}$ fluorescent siRNA (red) for 24h. Cells are immunostained (green) with GFAP (A) or ED1 (D) to evidence astroglia and microglia, respectively. Fluorescent siRNA in astroglia (B) and microglia (E) cultures. Merged images (C, F) illustrate siRNA cell transfection. The nucleus of the cells is shown in blue after Hoecht staining (E, F). Bar scale: $25 \mu \mathrm{m}$.

Figure 7. siRNA does not increase Stat1 expression in NIH-3T3 cells. A,B) No induction of Stat1 is observed after siRNA (100 nM) treatment in epithelial 3T3 cells $(n=4)$. C, D) However, these cells showed silencing responses after the siRNA treatment, as shown by reduced $\mathrm{p} 21$ protein expression after treatment with anti-p21 siRNA $(\mathrm{n}=5) . * \mathrm{p}<0.05$ versus vehicle (oligofectamine) (-).

Figure 8. TLR7 and TLR3 mRNA expression in the different cell cultures, and effect of the TLR3 agonist PIC. A) TLR7 mRNA expression $(n=4-5)$ and B) TLR3 mRNA expression $(n=2-3)$ in primary astroglia cultures (primary), purified astroglia cultures (astroglia), purified microglia (microglia) and 3T3 cells show higher expression of TLR7 mRNA in microglia than in cultures containing astroglia and 3T3 cells. The reverse situation is found for TLR3 mRNA, and the highest expression is found in primary astroglia cultures. Comparatively, low TLR3 and TLR7 mRNA expression is found in 3T3 cells. Results are expressed as relative mRNA levels in relation to the value obtained in pure astrocytes $(*$ $\mathrm{p}<0.05, * * \mathrm{p}<0.01)$. C) siRNA (100 nM, or $3.3 \mu \mathrm{M}$, which is approximately equivalent to 50 $\mu \mathrm{g} / \mathrm{mL})$ or PIC $(50 \mu \mathrm{g} / \mathrm{mL})$ treatment increases the level of TLR3 mRNA expression at $24 \mathrm{~h}$ 
$(\mathrm{n}=3-4)$ in primary astroglia cultures. D) PIC $(100 \mu \mathrm{g} / \mathrm{mL})$ induces high IFN- $\beta$ release at $24 \mathrm{~h}$ in primary astroglia $(\mathrm{n}=3)$ and purified astroglia, but the induction is comparatively very low in microglia. E) PIC $(100 \mu \mathrm{g} / \mathrm{mL})$ and certain siRNAs $(100 \mathrm{nM})$ induce the expression of Stat1, Cox-2 and VCAM-1 at $24 \mathrm{~h}(\mathrm{n}=3)$. The effects of unmodified siRNA against $\mathrm{p} 21$ is prevented by O-methylation of Guanosine $(\mathrm{G})$, but not Uridine (U) nucleosides (n=3). F) Chloroquine $(50 \mu \mathrm{g} / \mathrm{mL})$ attenuates the effects of PIC $(100 \mu \mathrm{g} / \mathrm{mL})$ and siRNA $(100 \mathrm{nM})$ $(\mathrm{n}=3) . * \mathrm{p}<0.05 ; * * \mathrm{p}<0.01 ; * * * \mathrm{p}<0.001$ 


\section{Figure 1}

A
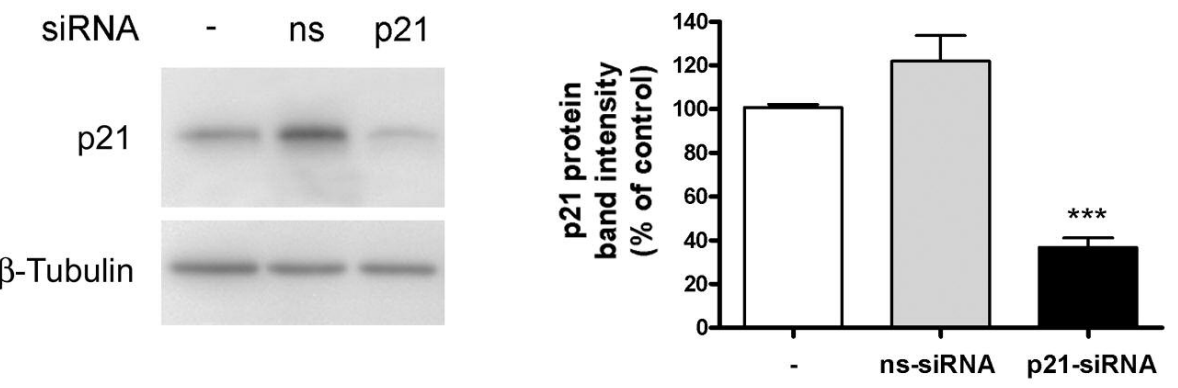

B
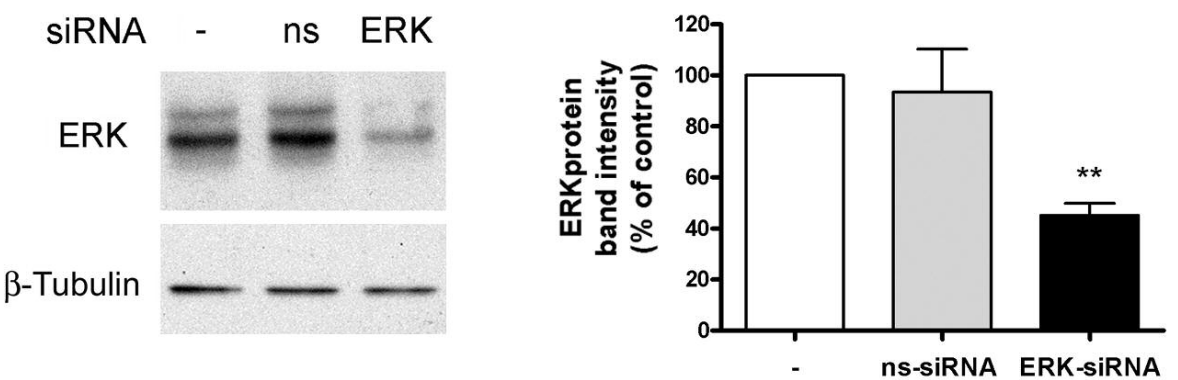

C
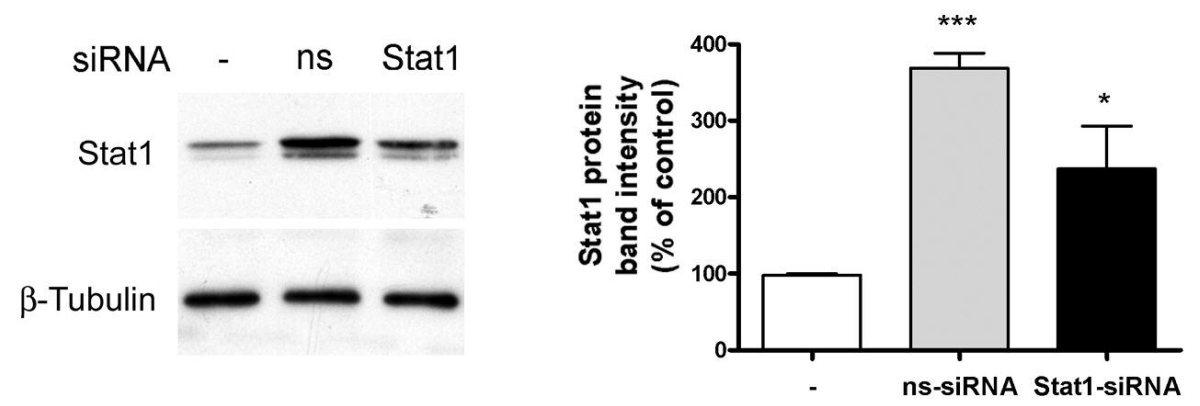

Specific siRNA sequences reduce the level of expression of the targeted proteins $119 \times 134 \mathrm{~mm}(300 \times 300$ DPI $)$ 
Figure 2

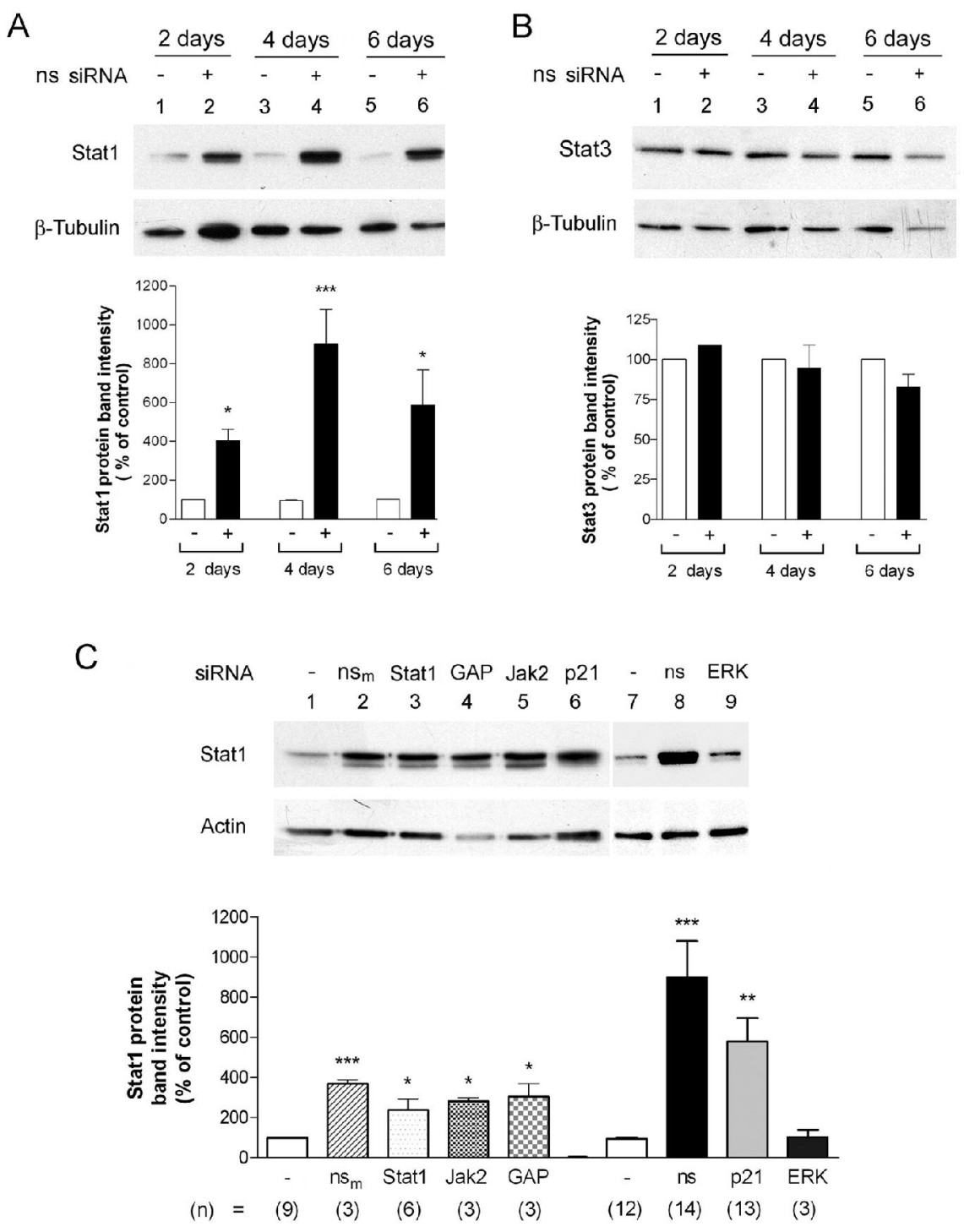

SiRNA sequences induce the expression of Stat1 in primary cultures of glia $140 \times 188 \mathrm{~mm}(300 \times 300 \mathrm{DPI})$

John Wiley \& Sons, Inc. 


\section{Figure 3}

A
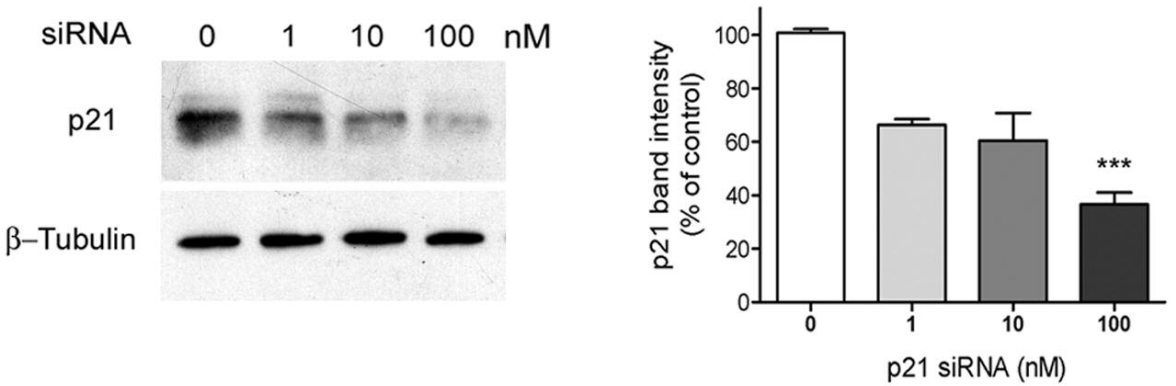

B
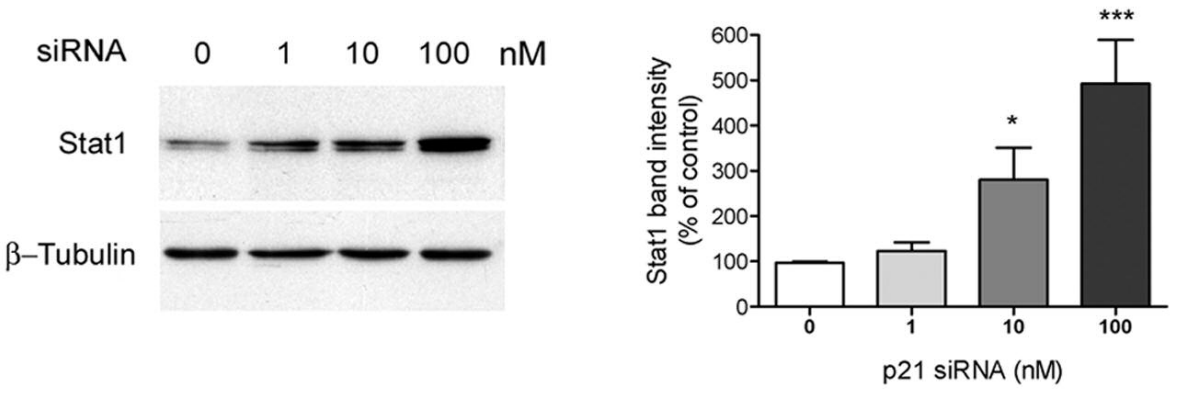

C
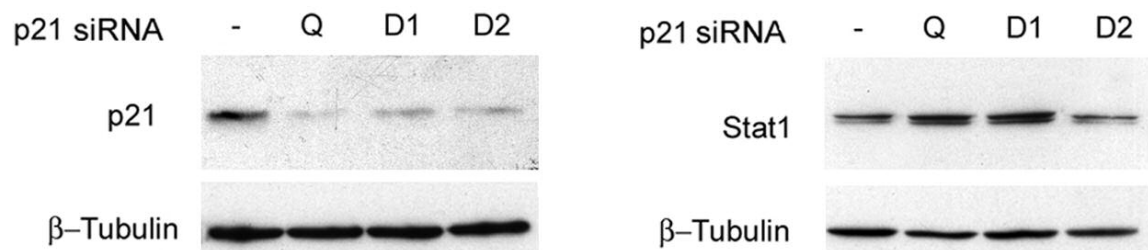

Stat1 protein-induction increases as a function of the siRNA concentration and it is dependent on the siRNA sequence, but independent of the silencing effect. $119 \times 138 \mathrm{~mm}(300 \times 300 \mathrm{DPI})$ 
Figure 4

A

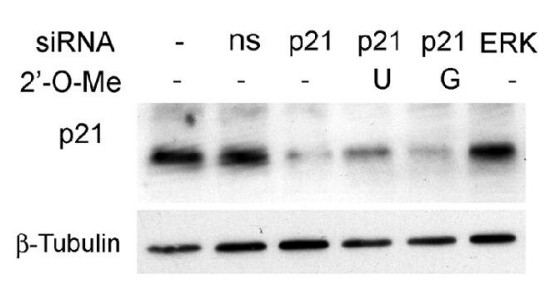

C

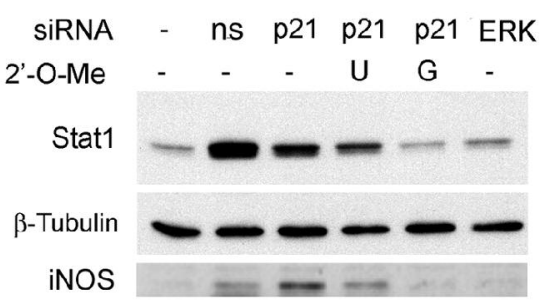

$E$

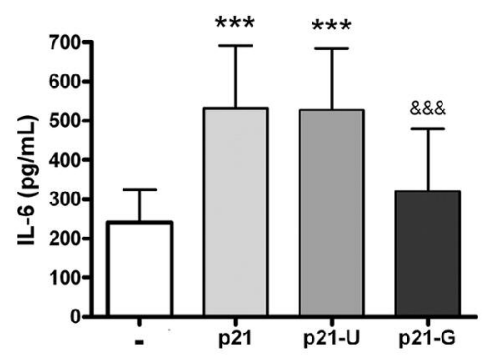

G

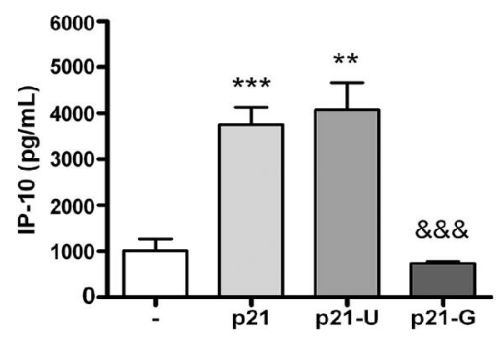

B

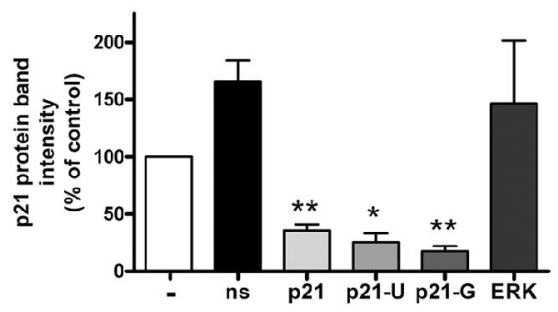

$\mathrm{D}$

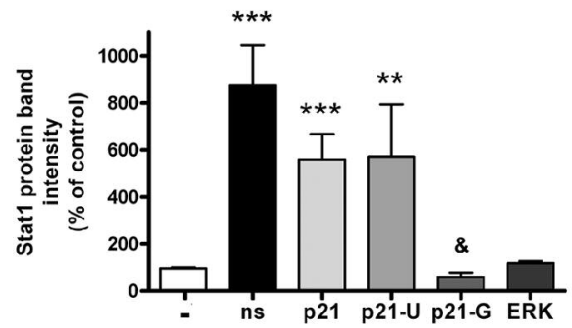

$\mathrm{F}$

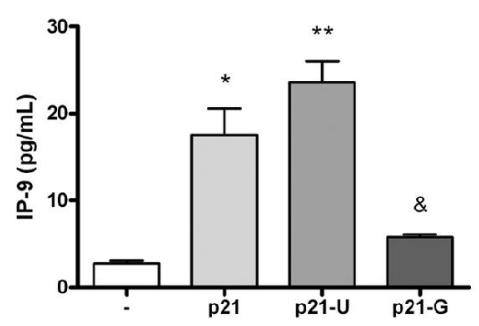

$\mathrm{H}$

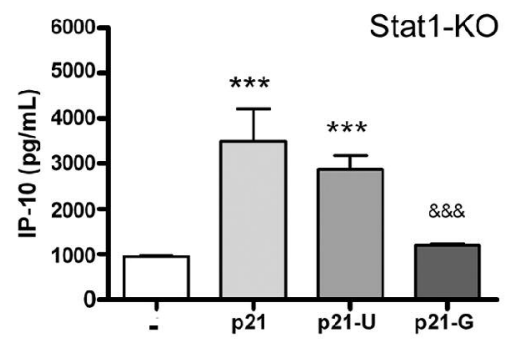

O'-methylation of certain nucleosides of the siRNA sense strand abrogates Stat1, chemokine and cytokine induction, without altering the silencing effect $140 \times 169 \mathrm{~mm}$ ( $300 \times 300$ DPI) 
Figure 5

A

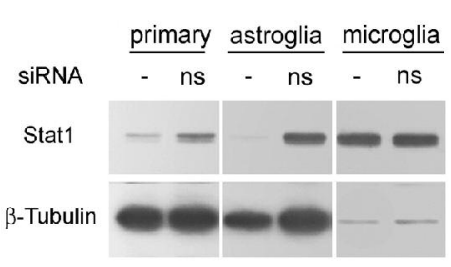

C

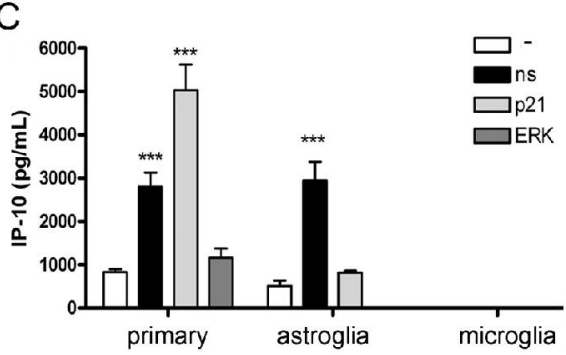

$\mathrm{E}$

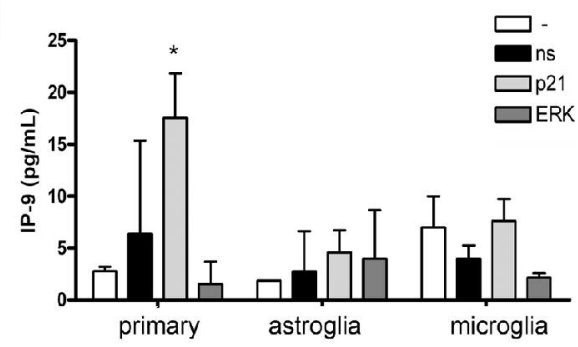

B

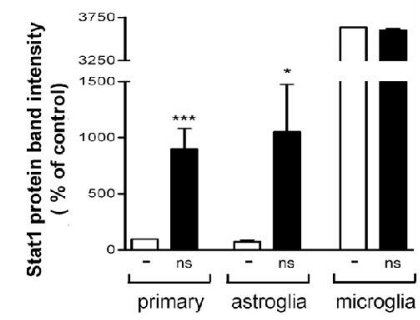

$\mathrm{D}$

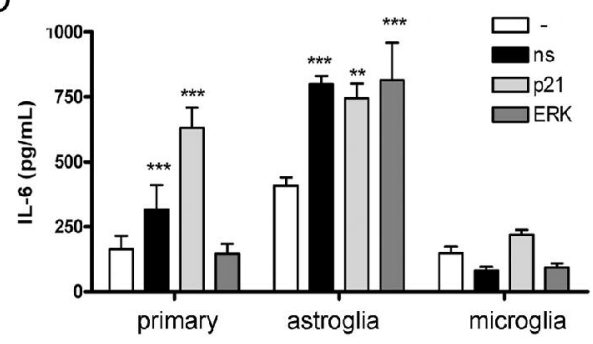

$\mathrm{F}$

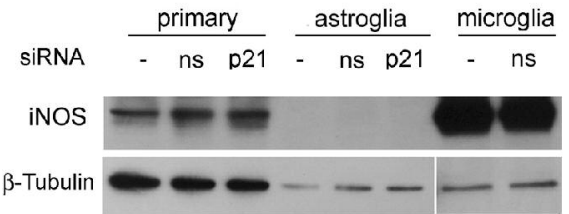

SiRNA induces Stat1 expression and cytokine and chemokine release depending on the type of glia culture $160 \times 149 \mathrm{~mm}(300 \times 300 \mathrm{DPI})$ 
Figure 6
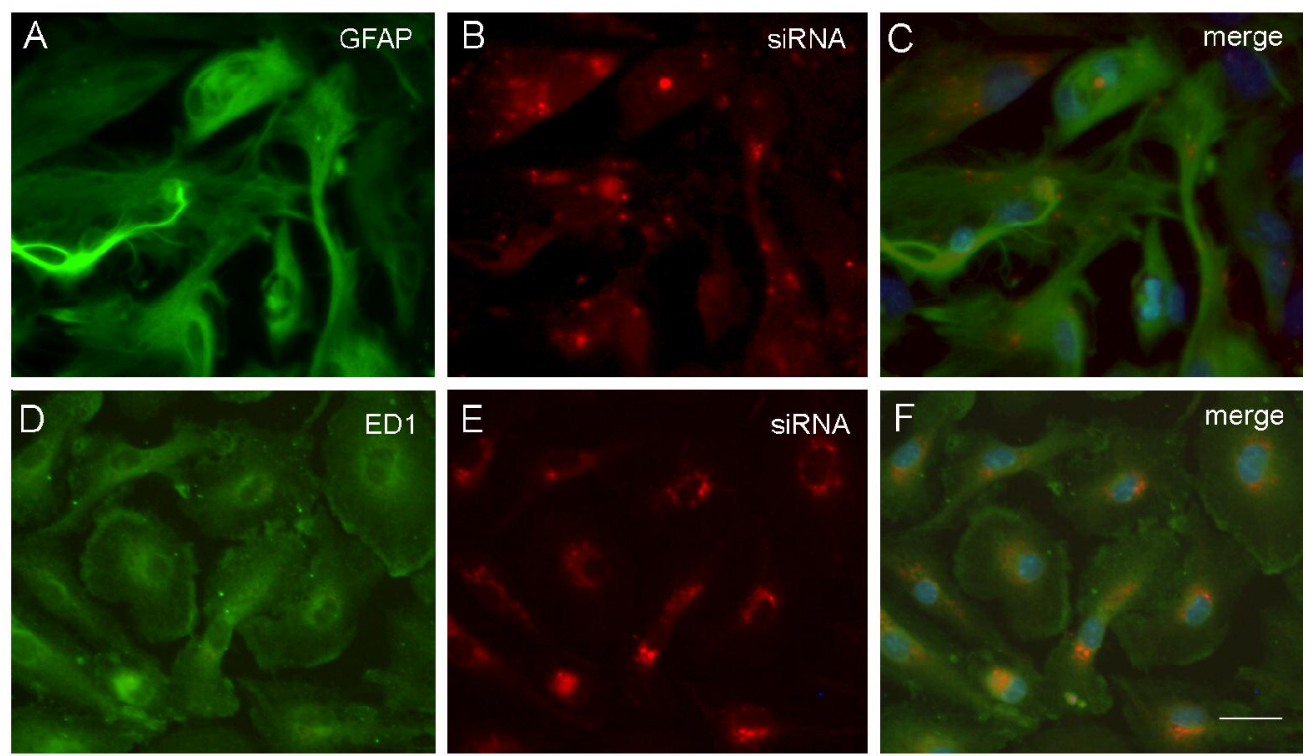

SiRNA is internalized into astrocytes and microglia $140 \times 90 \mathrm{~mm}(300 \times 300$ DPI) 
Figure 7

A

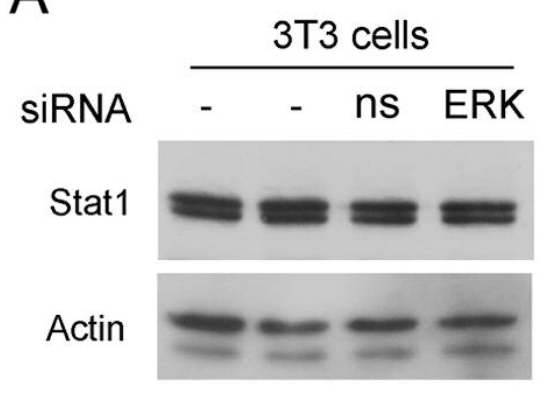

C

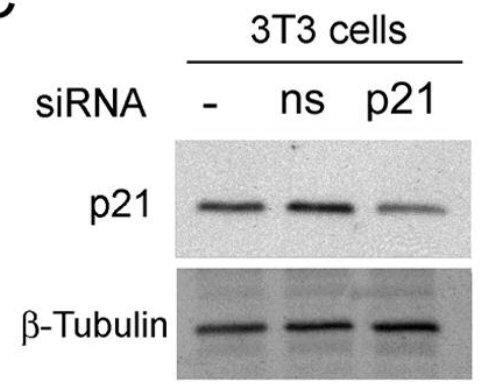

B

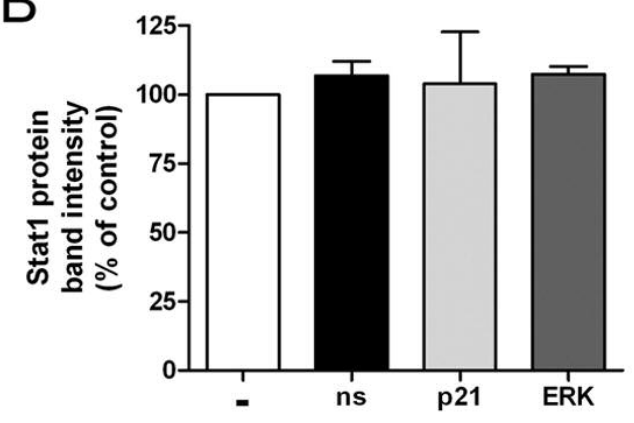

D

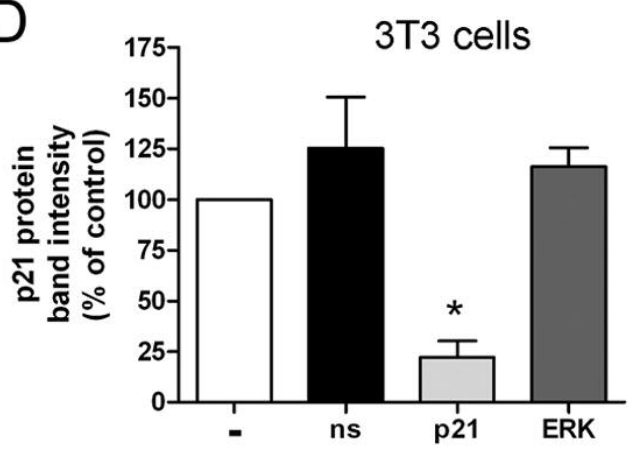

SiRNA does not increase Stat1 expression in NIH-3T3 cells $94 \times 78 \mathrm{~mm}(300 \times 300 \mathrm{DPI})$ 
Figure 8

A

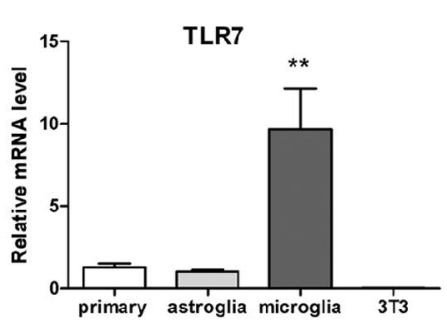

B

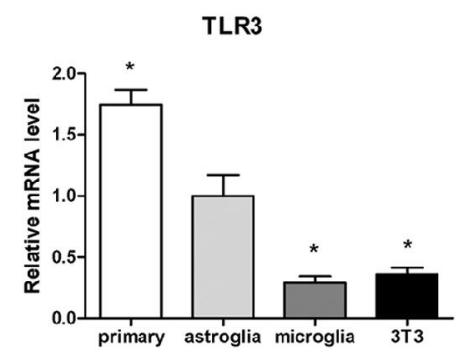

C

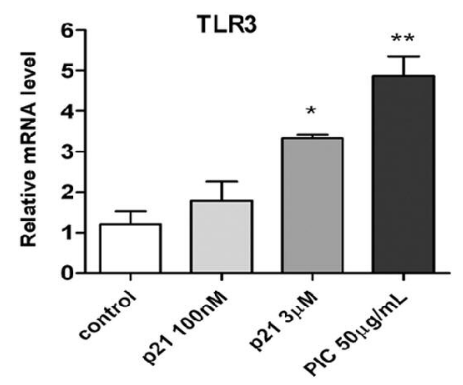

$\mathrm{D}$

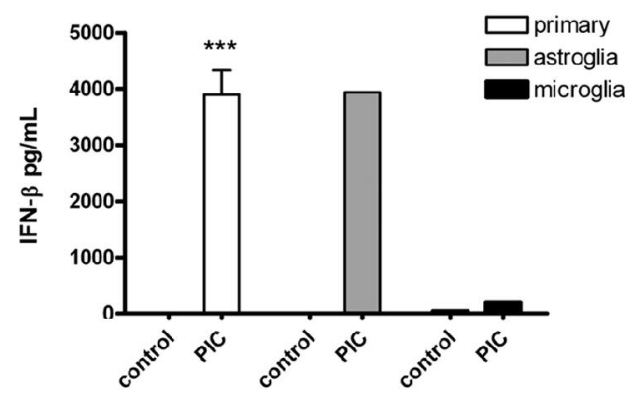

$\mathrm{E}$

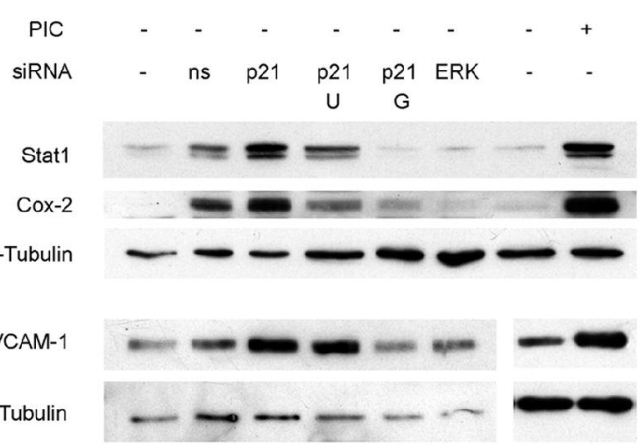

$\mathrm{F}$

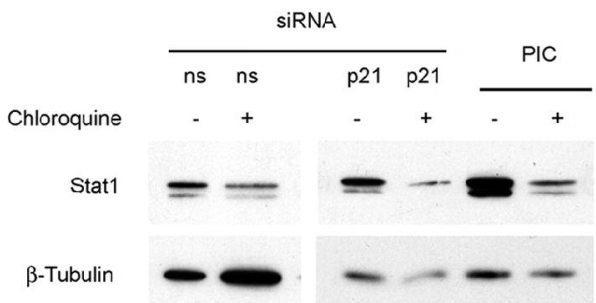

TLR7 and TLR3 mRNA expression in the different cell cultures, and effect of the TLR3 agonist PIC

$140 \times 150 \mathrm{~mm}(300 \times 300 \mathrm{DPI})$ 